\title{
Development of Environmentally Safe Pharmaceutical Treatment Technology of Urban Territories Wastewater
}

\author{
Tamara Krasnova ${ }^{1, *}$, Natalia Gora $^{1}$, and Nadezhda Golubeva ${ }^{1}$ \\ ${ }^{1}$ Kemerovo State University, 630099 Russia
}

\begin{abstract}
At present, one of the most important problems is the growing of environment pollution of Urban Development. Wastewater treatment generated in the manufacture of medicines and biologically active additives is of great importance for water bodies' sanitary protection. The sorption method provides a high degree of weakly concentrated wastewater purification, the absence of secondary pollution and the possibility of returning valuable components and water to the production. The purpose of the study was to develop an adsorption technology for wastewater treatment in the pharmaceutical industry containing flavonoids using semi-coke. Results of the study: The results of complex studies of the flavonoids quercetin adsorption and rutin on active charcoals differing in raw materials, method of production, structure and chemistry of the surface are presented. The main equilibrium, kinetic and dynamic process parameters are calculated for engineering calculations. Importance of the research: The technology of wastewater adsorption treatment from pharmaceutical industries with subsequent regeneration of active coals is proposed, which will provide protection against water pollution and resource saving. The performed work showed the prospects of using the semi-coke "Puroolat-Standard", which is characterized by higher adsorption capacity and lower cost
\end{abstract}

\section{Introduction}

The intensive industry development has a negative impact on the environment. The main sources of aquatic environment pollution by organic components are industrial wastewater. The composition of industrial waste water depends on the nature of the production process. Pharmaceutical industries wastewater may contain various flavonoid compounds, which are a fairly widespread group of polyphenols used to produce medicines with a wide range of pharmacological effects.

Among the methods used to extract valuable dissolved components from wastewater, sorption purification became widespread. The advantage of sorption cleaning is the possibility of adsorption of multicomponent mixtures' substances, high efficiency of weakly concentrated wastewater purification and the possibility of creating environmentally friendly production facilities by returning purified water and valuable components to production.

\footnotetext{
*Corresponding author: michmacha@mail.ru
} 
Most often, active carbons obtained from wood, pits of fruit trees, etc., which are of high cost, are used as adsorption materials and the scale of their application are limited (M.L. Shchipko, A.O. Eremina \& V.V. Golovina, 2008). At present, domestic industry mastered the production of cheap filter materials - semi-coke. The most promising of these is the semicoke "Puroolat-Standard", which is produced on the basis of low-ash anthracite and has a high natural porosity. The aim of the study is to develop an adsorption technology for wastewater treatment in the pharmaceutical industry containing flavonoids using semi-coke. To achieve this goal, the following tasks are defined:

- carry out a complex study to determine the features, regularities and mechanism of flavonoids adsorption on coals with different structure and chemistry of the surface and determine the adsorption equilibrium and kinetic parameters necessary for engineering calculations of the adsorption plant;

- to carry out modeling of the flavonoid adsorption process dynamics using the fundamental adsorption equations, to calculate the parameters of the adsorption unit and the modes of the process;

- develop a technology for the recovery of adsorbents in order to reuse them.

The literature contains data on the study of flavonoids sorption extraction on a number of different sorbents. Sorption of flavonoids by ion-exchange materials - anion exchangers of different porosity in OH- and CI-form (NA Udalova et al., 2008) was studied. In (E.O. Korabelnikova et al., 2014) work the use of polymeric and organo-inorganic siliceous sorbents for extracting quercetin was investigated. The available data on the sorption extraction of flavonoids are fragmentary and fragmentary $[1,4,5]$.

Information on flavonoids adsorption from aqueous solutions on carbon sorbents is absent, which does not allow even to make a conclusion about the principle possibility of using active carbons for their extraction. At the same time, in order to create an effective sorption technology for wastewater treatment of pharmaceutical industries on carbon sorbents, it is necessary to have data on the adsorption behavior of the flavonoid-water-active carbon system, the mechanisms of adsorption and mass transfer, the process dynamic characteristics, the possibility of reducing the adsorption capacity of waste sorbents.

\section{Materials and Methods}

The research subjects were active carbons AG-OV-1, Puroolat-Standard and model solutions of the most common bioantioxidants of flavonoids - quercetin and routine.

The study of regularities and features of the adsorption extraction process of organic substances was carried out in the concentration range $20-1900 \mathrm{mg} / \mathrm{dm} 3$ under the static conditions. Previously, a series of experiments determined the duration of adsorption equilibrium establishment, which is not less than 9 hours.

The calibration curves are linear in the optical density range $0-0.90(\mathrm{R} 2 \geq 0.97)[1]$.

The kinetics of flavonoids adsorption was studied in the model solutions of quercetin and rutin with a concentration of the studied component equal to $20 \mathrm{mg} / \mathrm{dm} 3$. The contact time of phenolic compound solution with the samples of the carbon sorbent ranged from 1 minute to 6 hours.

During the adsorption dynamics studying, model solutions were passed through a glass column $4 \mathrm{sm}$ in diameter, with a sorbent layer length of $1 \mathrm{~m}$ and a space velocity of $4.6 \mathrm{sm} 3$ / $\min$.

The concentration of flavonoids in solutions was controlled spectrophotometrically by their own absorption. The optical density was determined on the SF-46 instrument (thickness of the light-absorbing layer $10 \mathrm{~mm}$ and wavelength for quercetin $340 \mathrm{~nm}$ and routine 380 $\mathrm{nm})$. To select a rational method for reducing the adsorption capacity of a carbon sorbent after extracting flavonoids, active carbon regeneration was carried out for 3.5 hours under 
laboratory conditions at a temperature of $180^{\circ} \mathrm{C}$ steam and $300^{\circ} \mathrm{C}$ air and a regenerating agent consumption of $100 \mathrm{sm} 3 / \mathrm{min}$. Three cycles of adsorption-regeneration were carried out.

\section{Results}

According to the obtained experimental data on the quercetin and rutin adsorption by carbon sorbents, adsorption isotherms were constructed from solutions of individual substances (Fig. $1)$.

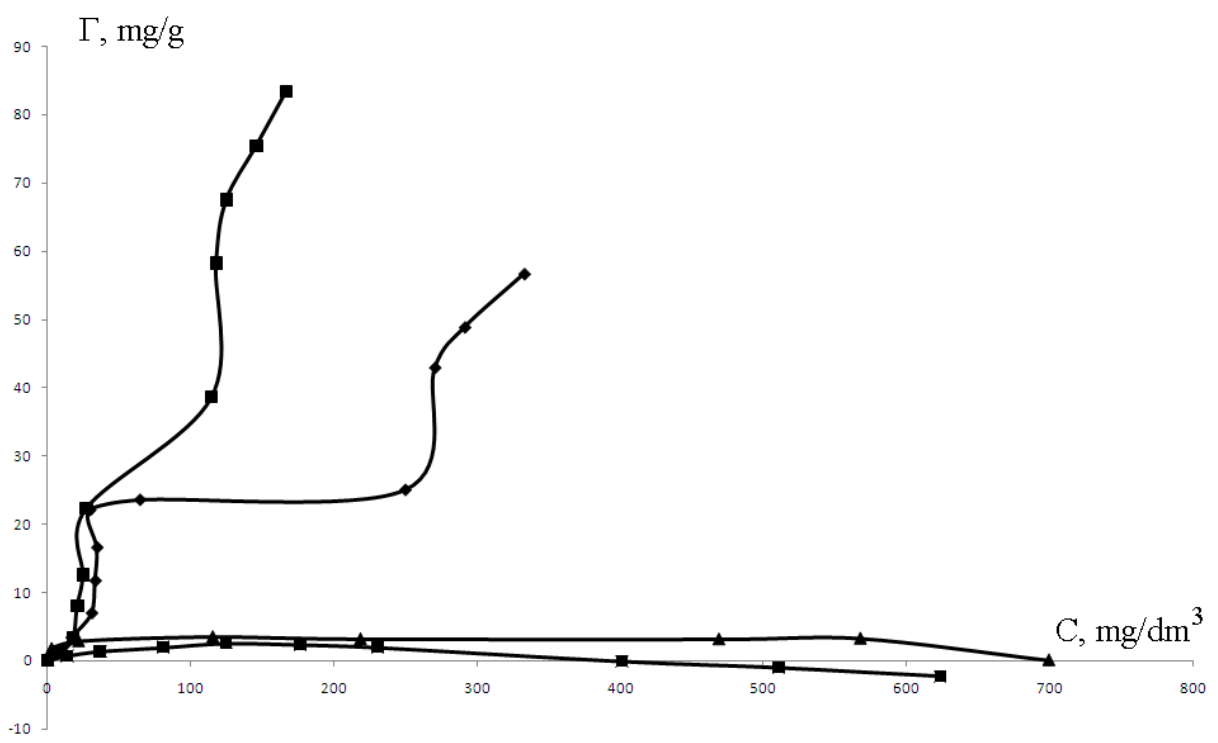

Fig. 1. Isotherms of flavonoids adsorption on active coals: "Puroolate-Standard" - quercetin (1), routine (3); AG-OV-1 - quercetin (2), routine (4)

The initial section of the quercetin adsorption isotherm in the process of extracting the flavonoid studied by the "Puroolat-Standard" brand semi-coke is bent relative to the concentration axis and refers to the S-type isotherms according to the Gils classification., An inflection point is obtained in the process of substance concentration increasing. It gives the isotherm a characteristic S-shape. The observed inflection and further rise of the isotherm are typical for adsorption in large mesopores and macropores. Adsorption increases rapidly as the solubility limit is reached [3].

In the case of quercetin adsorption on the carbon sorbent AG-OV-1, the process is described by the L-type isotherm according to the Gils classification, characterized by a concave line with respect to the concentration axis.

The isotherm bends as the concentration increases takes the form of a plateau, and then grows.

Based on the experimental data using adsorption equations of Langmuir and BET (G.D. Parfitt and C.H. Rochester, 1983), the adsorption parameters necessary for engineering calculations are calculated (Table 1,2). 
Table 1. Flavonoid adsorption parameters calculated with a help of the Langmuir equation

\begin{tabular}{|c|c|c|c|c|c|c|}
\hline Coal grade & \multicolumn{3}{|c|}{ Quercetin } & \multicolumn{3}{c|}{ Rutin } \\
\cline { 2 - 7 } & $\begin{array}{c}-\mathrm{G}, \\
\mathrm{kJ} / \mathrm{mol}\end{array}$ & $\begin{array}{c}\Gamma_{\max }, \\
\mathrm{mmol} \\
/ \mathrm{g}\end{array}$ & $\mathrm{R}^{2}$ & $\begin{array}{c}-\mathrm{G}, \\
\mathrm{kJ} / \mathrm{mol}\end{array}$ & $\begin{array}{c}\Gamma_{\max }, \\
\mathrm{mmol} / \\
\mathrm{g}\end{array}$ & $\mathrm{R}^{2}$ \\
\hline AG-OV-1 & 29,36 & 0,16 & 0.99 & 29,08 & 0,04 & 0.98 \\
\hline $\begin{array}{c}\text { Puroolat- } \\
\text { Standard }\end{array}$ & 27,59 & 0,58 & 0.99 & 41,54 & 0,05 & 0.97 \\
\hline
\end{tabular}

Table 2. Flavonoid adsorption parameters calculated using the BET equation

\begin{tabular}{|c|c|c|c|c|c|c|}
\hline Coal grade & \multicolumn{3}{|c|}{ Quercetin } & \multicolumn{3}{c|}{ Rutin } \\
\hline & $\begin{array}{c}\mathrm{Q}, \\
\mathrm{kJ} / \mathrm{mol}\end{array}$ & $\begin{array}{c}\Gamma_{\max }, \\
\mathrm{mmol} / \\
\mathrm{g}\end{array}$ & $\mathrm{R}^{2}$ & $\begin{array}{c}\mathrm{Q}, \\
\mathrm{kJ} / \mathrm{mol}\end{array}$ & $\begin{array}{c}\Gamma_{\max }, \\
\mathrm{mmol} / \\
\mathrm{g}\end{array}$ & $\mathrm{R}^{2}$ \\
\hline AG-OV-1 & 2,47 & 0,15 & 0.98 & 9,92 & 0,038 & 0.98 \\
\hline $\begin{array}{c}\text { Puroolat- } \\
\text { Standard }\end{array}$ & 2,49 & 0,55 & 0.99 & 16,96 & 0,051 & 0.98 \\
\hline
\end{tabular}

The presented data, as well as the low cost of semi-coke, make it possible to recommend Puroolat-Standard for further research. To determine the mechanism of mass transfer, which is one of the basic factors that determines the choice of the adsorption filter's operating mode, the kinetics of the adsorption process in active carbon-water-flavonoid systems was studied. The dimensionless kinetic parameters of $\mathrm{T}$ were determined. It is established that the rate of flavonoids adsorption is controlled by external mass transfer. The coefficient of the external diffusion mass transfer is calculated. The experimental kinetic curves of quercetin adsorption are presented in Fig. 2.

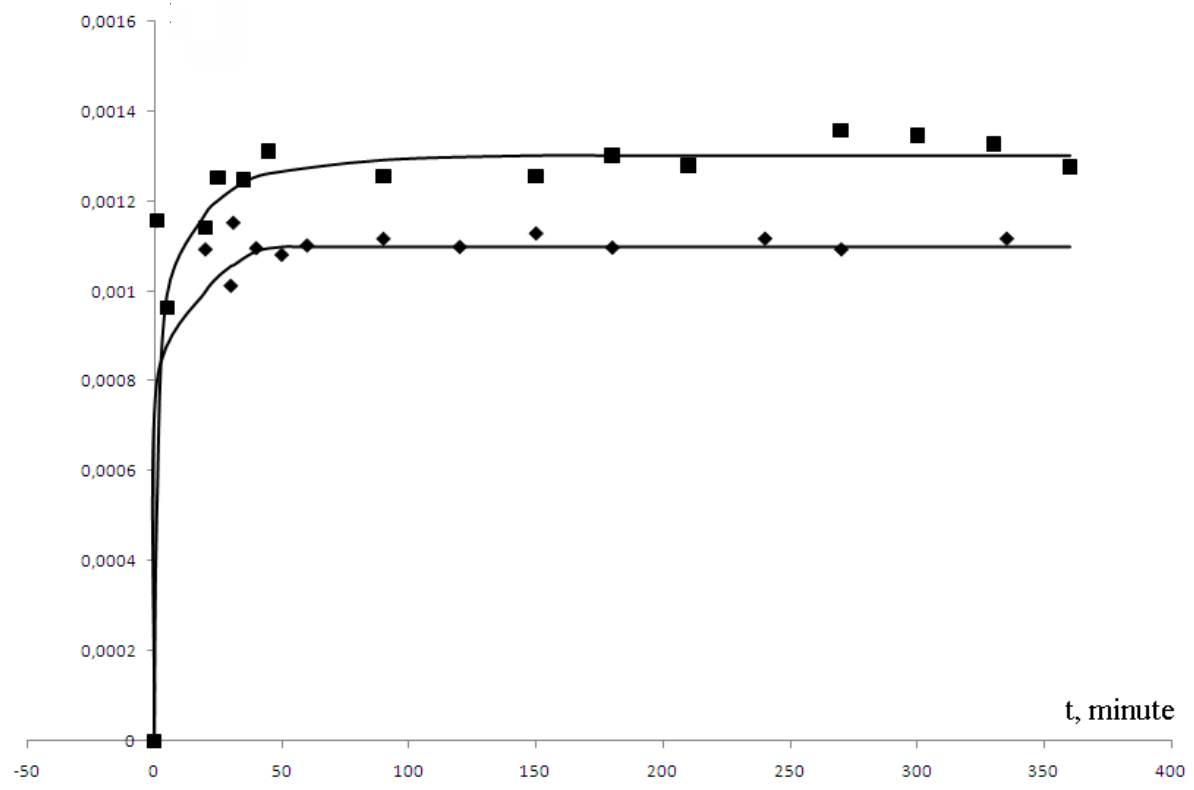

Fig. 2. Kinetic curves of quercetin adsorption (1) and routine (2) with activated carbon of the brand "Puroolat-Standard" 
On the basis of experimental data, to obtain information on the correspondence of the studied carbon sorbents' granules to the one of the two porous structure models, the degree of the adsorption equilibrium achievement is calculated.

Figures 3 to 4 show the experimentally obtained curves of $\gamma$ dependence on the mixing time $\tau$ of active carbon with solutions of flavonoids and the dependence of the dimensionless kinetic parameter $(\mathrm{T})$ on $\tau$.
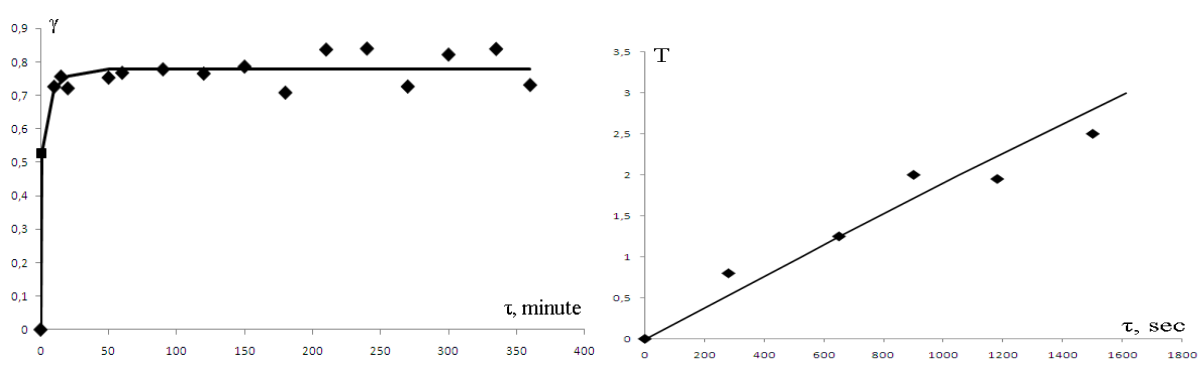

Fig.3. Kinetic curves of quercetin adsorption with activated carbon of the brand "PuroolatStandard" in the coordinates $\gamma-\tau(\mathrm{a})$ and $\mathrm{T}-\tau(\mathrm{b})$
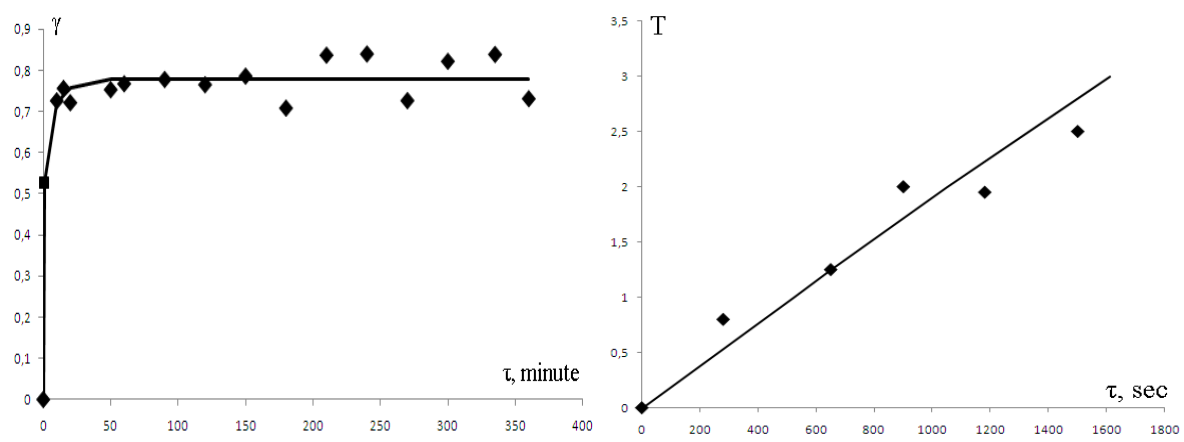

Fig.4. Kinetic curves of rutin adsorption with activated carbon of the brand "PuroolatStandard" in the coordinates $\gamma-\tau$ and $T-\tau$

The coefficients of external mass transfer of $\beta$-flavonoids are presented in Table 3 .

Table 3. Coefficients of external mass transfer of $\beta$-flavonoids

\begin{tabular}{|l|c|c|}
\hline \multicolumn{2}{|c|}{ Coefficient of external mass transfer, min $^{-1}$} & $\mathrm{R}^{2}$ \\
\hline quercetin & 0,0120 & 0,98 \\
\hline routine & 0,0120 & 0,99 \\
\hline
\end{tabular}

An important stage in the creation of sorption technology is the study of flavonoids dynamics. Figure 5 shows the experimental curve for flavonoids adsorption. 


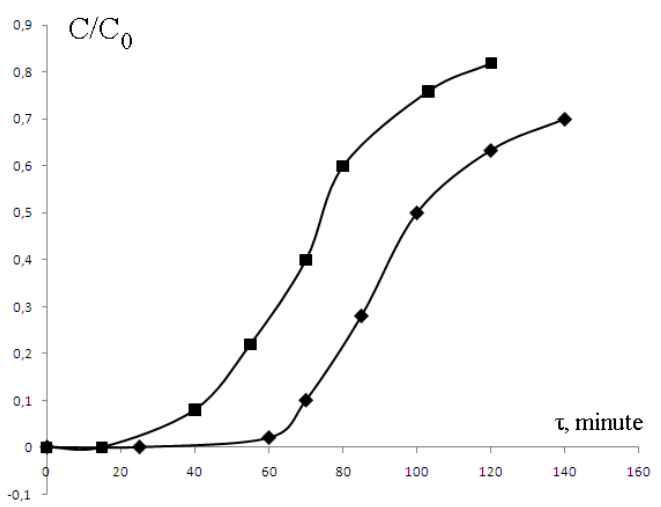

Fig. 5. Experimental output curves of rutin (1) and quercetin (2) adsorption dynamics on the semi-coke "Puroolat-Standard"

Calculation of dynamics parameters, using the method of mathematical modeling on the basis of theoretical dependencies describing mass transfer, significantly reduces the volume of experimental studies. The modeling is based on the fundamental equation of the external diffusion dynamics of adsorption using experimental data on the statics and kinetics of the compounds adsorption under study on carbon sorbents:

$$
\sqrt{\tau}=\sqrt{\frac{G_{0}}{v C_{0}}} \cdot \sqrt{L}-b \sqrt{\frac{G_{0}}{\beta_{n} \cdot C_{0}}}
$$

To increase the economy and effectiveness of adsorption technologies use, it is necessary to regenerate spent carbon sorbents, which will make it possible to reuse adsorption materials. The results of the study showed an increase in the effectiveness of each method studied with respect to the second cycle of adsorption-regeneration. The most effective recovery of the Porolat-Standard carbon adsorption capacity is achieved by using lowtemperature thermal regeneration with air at a temperature of $300^{\circ} \mathrm{C}$ (Figure 6).
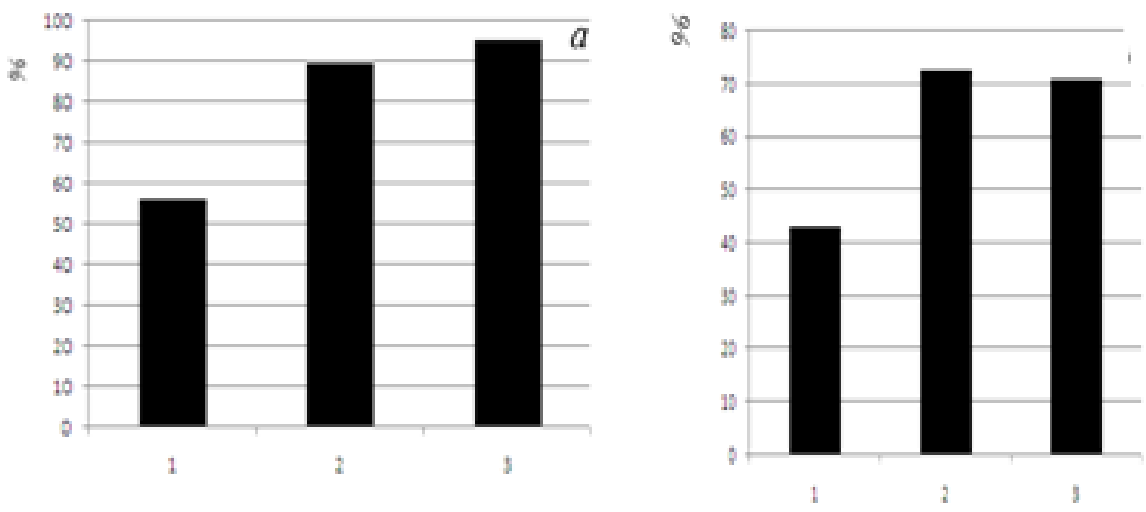

Fig. 6. The degree of the adsorption capacity recovery in relation to the flavonoids of the

"Puroolat-Standard" brand active carbon in the process of regeneration (100\% - adsorption capacity of the industrial sample): a - air regeneration $\left(300^{\circ} \mathrm{C}\right)$; b - steam regeneration $\left(180^{\circ} \mathrm{C}\right)$. 


\section{Discussion}

Based on the forms obtained flavonoid adsorption isotherms, we can assume the physical nature of the process, which are more determined for the carbon sorbent brand AG-OV-1by the dispersion, and for the semi-coke "Puroolat-Standard" specific interaction.

At the beginning of quercetin extracting on a semi-coke process, monomolecular adsorption predominates, then secondary active centers are formed, due to the interaction of adsorbate, which explains the kinks on isotherms and the presence of a second plateau. The interaction forces between adsorbed molecules promote further absorption manifesting a cooperative character (S.J. Gregg \& K.S.W. Sing, 1982). The formation of complexes is most likely due to the hydrogen bonds between quercetin molecules.

The shape of the experimental isotherm initial section of the rutin adsorption on the AGOV-1 sorbent refers to the L-type isotherms and on the brand "Puroolat-Standard" semi-coke to the H-type according to the Gils classification.

In these cases, there is practically no interaction between the extracted molecules on the active carbons surface. In this case, the L-type adsorption isotherms assume physical adsorption (G.D. Parfitt \& C.H. Rochester, 1983). The H-type isotherm makes it possible to assume the adsorbate and adsorbent particles are bound by stronger forces due to the arising chemical interaction.

Experimental study of the adsorption kinetics made it possible to determine the porous structure type of the sorbents studied. The dependence of the degree of the adsorption equilibrium achievement on time has a rectilinear character up to $\gamma=0.7-0.9$, which allows us to assume the coal granules used are of a quasi-homogeneous model and calculate the kinetics from this model. The quasi-homogeneous model is based on the idea the dissolved substance penetrating the adsorbent, interacts with it throughout the entire volume and during the entire residence time of the particle in the reaction zone. The sorbent grain can be considered as a system formed by a random interlacing of pores. The values of $\gamma$ indicate the adsorption of dissolved flavonoids inside the grain proceeds so quickly that it does not have a noticeable effect on the overall mass transfer rate.

The study of dynamics and mathematical modeling made it possible to establish the main parameters of the filter and the adsorption process modes: the height of the fixed bed and the size of the column, the length of the working layer, the length of the unused layer, the protective action coefficient, the duration of the column operation, and the amount of waste water to be cleaned, depending on the transmission speed.

The obtained results of the regeneration studies allow us to assume that the active carbon is both modified by the feed gas and by the organic substances themselves, which causes an increase in regeneration with respect to the second cycle. It should be noted that the effect of increased temperature on a char, especially in the oxidants presence (water vapor, oxygen), during the second cycle of regeneration, can cause partial burning out of organic matter on the surface, as well as the appearance of new adsorption centers (surface oxygen-containing groups) capable of interacting with polyphenolic compounds.

\section{Conclusions}

In the course of a comprehensive study, the mechanism and peculiarities of the flavonoids adsorption interaction with the carbon sorbents surface are established. Adsorption occurs due to the physical interaction of the active coal surface with recoverable substances, which is more pronounced in the dispersion interaction on the active carbon of AG-OV-1 grade, and in the process of extracted on the semi-coke "Puroolat-Standard" - in a specific one. Adsorption on carbon sorbents is characterized by both primary and secondary interactions. As adsorbed polyphenol molecules, secondary adsorption can act as active centers. 
A method is proposed for calculating the parameters of the column and the regimes of the adsorption process, based on the equation of the adsorption external diffusion dynamics for the case of a linear isotherm with the use of the adsorption constants of the DubininRadushkevich equation and kinetic data.

Based on the results of the adsorption process experimental and theoretical study and data on the sorbents regeneration, a technology for the flavonoids adsorption on the semi-coke "Puroolat-Standard" was developed. The developed adsorption technology of wastewater treatment from flavonoids will create in the pharmaceutical industry production with closed water rotation cycles, return the extracted flavonoids to production, and reduce the technogenic load on water bodies and ensure the rational use of natural resources.

\section{References}

1. M.L. Shchipko, A.O. Eremina, V.V. Golovina, Journal of Siberian Federal University, Chemistry 2, 1, 166-180 (2008)

2. N.A. Udalova, S.I. Karpov, V.F. Selemenev, I.A. Sharmar. Sorption and chromatography processes, 8 (2), 304-313 (2008)

3. E.O. Korabelnikova, S.I. Karpov, N.A. Belanova, O.O.Krizhanovskaya, L.A. Sinyaeva V.F. Selemenev, The study of the quercetin sorption kinetics on polymer and organicinorganic silicon-containing sorbents, Voronezh State University, Voronezh, Russia, 159-162 (2014).

4. Adsorption from solution at the Solid/Liquid Interface. Ed. G.D. Parfitt, C.H. Rochester, London-New York, Academic Press Publ, (1983).

5. S.J. Gregg, K.S.W. Sing, Adsorption, Surface Area and Porosity, Academic Press, London, (1982) 